\title{
Efficacy and safety of sofosbuvir-based therapies in patients with advanced liver disease in a real-life cohort
}

This article was published in the following Dove Press journal: Hepatic Medicine: Evidence and Research

\author{
Blaise K Kutala ${ }^{1,2}$ \\ Feryel Mouri' \\ Corinne Castelnau' \\ Valerie Bouton' \\ Nathalie Giuily' \\ Nathalie Boyer' \\ Tarik Asselah ${ }^{1,2}$ \\ Patrick Marcellin ${ }^{1,2}$
}

'Service d'hépatologie, Hopital Beaujon-APHP, Clichy, ${ }^{2}$ INSERM University of Paris Diderot, Paris, France

Correspondence: BK Kutala Service d'hépatologie, Hopital BeaujonAPHP, 100 Boulevard Général Leclerc, 92110 Clichy, France

Tel +33 I 57277561

Fax +33 I 47309440

Email blaise.kutala@bjn.aphp.fr
Background: The combination of sofosbuvir (SOF) with ribavirin (RBV) or daclatasvir (DCV) or simeprevir (SIM) for the treatment of patients infected by chronic hepatitis $\mathrm{C}$ (CHC) have led to significantly increased rates of sustained virological response (SVR). However, there is only limited data regarding factors associated with treatment failure in a "real-life" cohort.

Patients and methods: Consecutive treatment-naive and treatment-experienced patients F3-F4 were treated with SOF-based interferon-free therapy in our hospital from November 2013 to July 2015. The primary endpoint was the proportion of patients with sustained virological response 12 weeks after cessation of therapy (SVR12).

Results: A total of 167 treatment-naive and 207 treatment-experienced patients were treated and followed up for 2 years ( $n=383)$. Overall, 71\% were men; among them, 54\% had cirrhosis and the median age was 53 years. SVR 12 was achieved by $82 \%$ of the patients receiving SOF+RBV, $92 \%$ receiving SOF+DCV, and 79\% receiving SOF+SIM. Metavir F4 and albumin serum were found as independent risk factors associated with treatment failure in groups receiving $\mathrm{SOF}+\mathrm{RBV}$ ( $p=0.008$ and $p=0.001), \mathrm{SOF}+\mathrm{DCV}(p=0.038$ and $p=0.043)$, and $\mathrm{SOF}+\operatorname{SIM} \pm \operatorname{RBV}(p=0.014$ and $p=0.017$ ), respectively. The most common adverse events were fatigue, nausea, headache, and anemia. Three patients discontinued the treatment due to an adverse event.

Conclusion: These findings suggest that 12-week SOF-based regimen plus RBV or DCV or SIM is an efficacious and well-tolerated treatment in CHC patients with fibrosis stage F3-F4. Patients, who display risk factors for cirrhosis, should be referred to an experienced viral hepatitis center. Keywords: sofosbuvir, hepatitis C virus, interferon-free therapies, cirrhosis, advanced fibrosis

\section{Introduction}

Infection with hepatitis $\mathrm{C}$ virus (HCV) is a leading cause of chronic liver disease worldwide and, consequently, a major health burden. ${ }^{1,2}$ In Europe, it is estimated that 7.5-9 million individuals are chronically infected. ${ }^{3}$

Understanding the effectiveness of antiviral regimens in real-life settings is necessary for informed treatment decisions. Data and information issued from clinical trials may be limited in applicability to clinical practice where variations in patient characteristics, care faculty, and management cannot be controlled. Differences between real-life HCV treatment outcomes ("effectiveness") and clinical trials ("efficacy") often become apparent once these medications are prescribed to a broader population. ${ }^{4-6}$

Since 2013, the landscape of HCV treatment has rapidly changed with the arrival of new and highly potent direct-acting antivirals (DAAs), ${ }^{7,8}$ such as the protease inhibitor simeprevir (SIM), polymerase NS5B inhibitor, nucleoside analogue sofosbuvir (SOF), 
and NS5A inhibitor daclatasvir (DCV). Sustained virological response (SVR) rates reported in clinical trials with SOFbased regimens represent a substantial improvement over previous DAA regimens. Combinations of these molecules are associated with SVR rates higher than $90 \%$ in the general population and with a good safety. ${ }^{5,9-13}$ However, in real life, in contrast with the highly controlled setting of industry clinical trials, pooled SVR rates are $\sim 65 \%-80 \%$ in patients with advanced fibrosis treated with SOF. ${ }^{10,14,15}$

Thus the aims of this study were 1) to compare the efficacy and safety of combination of SOF-based therapies in a real-life cohort, including $\mathrm{CHC}$ patients with advanced fibrosis and 2) most important to reassess the influence of the previously identified risk factors of cirrhosis such as male gender, age $>50$ years, diabetes, and Metavir score F4 due to treatment failure in an independent cohort of $\mathrm{CHC}$ patients not treated with interferon (IFN) in Beaujon Hospital.

\section{Patients and methods Study design}

This was a retrospective, non-interventional, single-center, real-life cohort study carried out in $\mathrm{CHC}$ patients receiving SOF-based treatments in accordance with the countryspecific legal and regulatory requirements. The study was conducted in accordance with the ethical guidelines of the Declaration of Helsinki revised at 2013, actual Loi Jardé $\mathrm{n}^{\circ}$ 2012-300 du 5 mars 2012 (French legislation), and the protocol was approved by our institutional review board Comité de protection des personnes (CPP) - Ile de France V. According to the aforementioned French legislation, for an observational study (with standard practices and no additional intervention), inform consent is not required. However, patient's confidentiality was respected according to both the French legislation and the CPP statement.

\section{Study population}

We analyzed the clinical and laboratorical data of consecutive fibrosis stage F3-F4 patients with $\mathrm{CHC}$ treated in our hospital between November 2013 and July 2015. Treatments including SOF+ribavirin (RBV) or DCV+SOF or $\mathrm{SOF}+\mathrm{SIM}+\mathrm{RBV}$ were initiated in these patients according to the temporary authorization for use in France between September 2013 and July 2015 at the viral hepatitis referral center, Beaujon Hospital, France. In France, the temporary authorization for use was made in May 2013 for SOF, July 2013 for DCV, and October 2013 for SIM. This temporary authorization for use was indicated in patients with advanced disease (fibrosis stage F3/F4) and extrahepatic manifestations and for whom there is no appropriate treatment or awaiting liver transplantation.

All patients received an abdominal ultrasound and routine laboratory test prior to the beginning of therapy. Liver fibrosis was measured by liver biopsy or by using 2 non-invasive fibrosis tests: Fibroscan (Echosens, Paris, France) and combination of serum markers (Fibrotest). Consequently, patients with hepatocellular carcinoma (HCC), those without any advanced fibrosis, and those with a history of Child-Pugh C score, HIV infection, or other active hepatitis were excluded. All patients included in other national cohorts or studies (Cupilt and Hepater) or those who were awaiting liver transplantation were also excluded.

\section{Treatment}

The prescribed treatment was at the sole discretion of the practitioner and the treatment was available only after approval by the regulatory agency. Initially, the patients were treated individually. According to the temporary authorization for use and country requirements, patients received SOF (400 $\mathrm{mg})+\mathrm{RBV}(1200 \mathrm{mg}$ ) administered for 12 weeks or SOF (400 $\mathrm{mg})+\mathrm{DCV}$ (60 mg) for 12 weeks, or SOF (400 mg)+SIM (150 $\mathrm{mg}) \pm \mathrm{RBV}$ (1200 mg) administered for 12 weeks.

\section{Treatment response and safety measures}

Serum HCV RNA levels were assayed centrally by COBAS TaqMan HCV test, version 2.0 (Roche Molecular Systems), with a lower limit of quantification of $50 \mathrm{IU} / \mathrm{mL}$ and a lower limit of detection of $15 \mathrm{IU} / \mathrm{mL}$. HCV RNA levels were measured at baseline, every 4 weeks during treatment ranging from week 4 to week 12, and at weeks 4, 12, and 24 after the end of the treatment (EOT) period.

Adverse events (AEs) were collected from data source. Clinical laboratory tests and physical examinations were performed and monitored at screening, at baseline, and at scheduled visits throughout the treatment period.

\section{Outcomes}

The primary outcome was the efficacy of treatments, determined by virologic response 12 weeks after the end of treatment (SVR12).

Virologic response, SVR12, was defined as HCV RNA $<50 \mathrm{IU} / \mathrm{mL}, 12$ weeks following the EOT. Relapse was defined as serum HCV RNA > $50 \mathrm{IU} / \mathrm{mL}$ during the followup. Non-SVR12 was further categorized by the detectable HCV RNA in patients with EOT response (HCV RNA >50 $\mathrm{IU} / \mathrm{mL}$ at EOT). The second outcome was the safety evaluated by percentage of $\mathrm{AE}$ or serious $\mathrm{AE}$ (SAE) in the different combinations of treatment. 


\section{Statistical analysis}

Continuous variables were reported as medians and interquartile range and as percentages for categorical variables for baseline characteristics. We calculated the proportion of patients who had an SVR along with exact 2-sided 95\% confidence intervals ( $95 \%$ CIs) constructed with the use of the Clopper-Pearson method for each group that underwent combination treatment and for subgroups. Statistical comparison using the Chi-square test or Fisher's exact tests to assess differences between combinations was performed for overall SVR rate. In an exploratory analysis, we performed a multivariate logistic-regression analysis involving baseline characteristics, using a stepwise procedure to identify independent predictors of an SVR at week 12 following the EOT.

All statistical analyses were performed with SAS software (SAS Institute, Cary, NC, USA), version 9.3.

\section{Results}

From November 1, 2013, to July 30, 2015, 634 patients with $\mathrm{CHC}$ were treated with SOF-based IFN-free treatment. Among them, 251 patients were excluded: 167 were already included in other national cohorts or others clinical protocols, 38 was diagnosed as F1-F2 at baseline and most were treated for extrahepatic manifestations, 34 did not meet the inclusion criteria, and 12 had missing data. Overall, 383 patients were included and initiated IFN-free SOF-based treatment: $\mathrm{SOF}+\mathrm{RBV}$ for 12 weeks $(\mathrm{n}=161), \mathrm{SOF}+\mathrm{DCV}$ for 12 weeks $(n=144)$, and SOF+SIM for 12 weeks $(n=78)$. Baseline clinical characteristics were balanced, except that more Caucasians and patients with genotype 4 were treated with $\mathrm{SOF}+\mathrm{SIM} \pm \mathrm{RBV}$ than with the other combinations (Table 1). Among the 102 (27\%) patients who had no liver biopsy, 68 (67\%) had severe fibrosis (F3) according to the Fibroscan $(>9.5 \mathrm{kPa})$ or Fibrotest score $(>0.59)$ and $34(33 \%)$ had clinical evidence of cirrhosis.

\section{Efficacy of different combinations}

Overall 383 patients included, 322 had a SVR 12 weeks after treatment, $44(16 \%)$ did not have a SVR12, 4 were lost to follow-up after post-treatment at week 12 (2 in SOF+RBV, 1 in $\mathrm{SOF}+\mathrm{DCV}$ and 1 in $\mathrm{SOF}+\mathrm{SIM} \pm \mathrm{RBV})$, and $14(4 \%)$ patients had treatment discontinuation. Among the 383 patients who received 12 weeks of combination therapy, 132 patients (82\%; 95\% CI, 76-88) in SOF+RBV, 132 (92\%; 95\%

Table I Demographic and clinical characteristics of 383 patients at baseline

\begin{tabular}{|c|c|c|c|c|c|c|c|}
\hline & & SOF+RBV & SOF+DCV & SOF+SIM $\pm R B V$ & $\underline{p \text {-value }}$ & & \\
\hline & $N=383$ & $n=|6|$ & $n=144$ & $n=78$ & (I6I vs I44) & (144 vs 78$)$ & ( 161 vs 78$)$ \\
\hline Men & 27 (7I\%) & II4 (7I\%) & 95 (67\%) & $62(79 \%)$ & NS & 0.055 & NS \\
\hline Age, median [IQR] & $53[47-72]$ & 53 [45-69] & 54 [47-7II] & 53 [49-72] & NS & NS & NS \\
\hline Caucasian & 306 (80\%) & II 17 (73\%) & II 4 (79\%) & 76 (97\%) & NS & 0.001 & 0.001 \\
\hline Diabetes & 45 (12\%) & $22(14 \%)$ & $13(10 \%)$ & $9(12 \%)$ & NS & NS & NS \\
\hline AST/ALT ratio & $0.92[0.79-1.2]$ & $0.91[0.82-1.3]$ & $0.88[0.78-1.2]$ & $0.96[0.77-1.2]$ & NS & $0.06 \mathrm{I}$ & NS \\
\hline Albumin (g/L) & $4 \mid[39-46]$ & $40[38-45]$ & $42[39-46]$ & $40[40-46]$ & NS & NS & NS \\
\hline Bilirubin $(\mu \mathrm{mol} / \mathrm{L})$ & $15[11-19]$ & $16[12-18]$ & $15[1 \mid-18]$ & $16[11-19]$ & NS & NS & NS \\
\hline Creatinine $(\mu \mathrm{mol} / \mathrm{L})$ & $74[68-79]$ & 73 [70-82] & $75[68-80]$ & $74[65-75]$ & NS & NS & NS \\
\hline Platelets count (109/L) & $148[13 \mid-181]$ & 147 [134-177] & $144[128-|8|]$ & 151 [112-168] & 0.059 & 0.034 & NS \\
\hline Prothrombin (\%) & $79[72-92]$ & 75 [68-92] & $81[7|-9|]$ & 80 [73-89] & NS & NS & NS \\
\hline HCV RNA $\left(\log _{10} I U / m L\right)$ & $6[5.7-6.3]$ & $5.9[5.6-6.3]$ & $6[5.8-6.2]$ & $6[5.7-6.1]$ & NS & NS & NS \\
\hline Treatment response $\mathrm{n}(\%)$ & $207(54 \%)$ & 95 (59\%) & $63(44 \%)$ & 49 (63\%) & 0.042 & 0.007 & NS \\
\hline Null responder & $68(33 \%)$ & $25(26 \%)$ & $23(36 \%)$ & $20(4 \mid \%)$ & & & \\
\hline Partial responder/relapse & $133(64 \%)$ & $66(70 \%)$ & 40 (63\%) & $27(55 \%)$ & & & \\
\hline Prior response unknown & $6(3 \%)$ & $4(4 \%)$ & 0 & $2(4 \%)$ & & & \\
\hline \multicolumn{8}{|l|}{ Genotype n (\%) } \\
\hline Genotype I & $236(62 \%)$ & $120(75 \%)$ & $102(7 \mid \%)$ & $14(18 \%)$ & NS & 0.001 & 0.001 \\
\hline Genotype 2 & $38(10 \%)$ & $13(8 \%)$ & $23(16 \%)$ & $2(3 \%)$ & & & \\
\hline Genotype 3 & $23(6 \%)$ & $8(5 \%)$ & $15(10 \%)$ & $(0 \%)$ & & & \\
\hline Genotype 4 & $86(22 \%)$ & $20(12 \%)$ & $4(3 \%)$ & $62(79 \%)$ & & & \\
\hline IL28B genotype CC n (\%) & II $3(30 \%)$ & $45(28 \%)$ & $53(37 \%)$ & $15(19 \%)$ & 0.189 & 0.004 & 0.133 \\
\hline \multicolumn{8}{|l|}{ Metavir score } \\
\hline $\mathrm{F} 4$ & $206(54 \%)$ & $92(57 \%)$ & $62(43 \%)$ & $52(66 \%)$ & 0.047 & 0.001 & 0.190 \\
\hline Liver biopsy & $28 \mathrm{I}(73 \%)$ & 119 (74\%) & 106 (74\%) & 56 (72\%) & NS & NS & NS \\
\hline
\end{tabular}

Notes: Data are presented as (\%) or median [IQR], unless otherwise noted. See "Methods" section for definition of Metavir score.

Abbreviations: ALT, alanine aminotransferase; AST, aspartate aminotransferase; SOF, sofosbuvir; RBV, ribavirin; DCV, daclatasvir; SIM, simeprevir; IL, interleukin; NS, not significant; HCV, hepatitis $C$ virus; IQR, interquartile range. 
CI, 86-95) in SOF+DCV, and $62(79 \% ; 95 \% \mathrm{CI}, 70-88)$ in $\mathrm{SOF}+\mathrm{SIM} \pm \mathrm{RBV}$ reached an SVR12 after the cessation of the treatment (Table 2). Among the patients with treatment discontinuation, 11 stopped the treatment due to other reasons not related to liver disease and 3 related to liver disease. Overall, 44 patients did not respond to the treatment. The combination of SOF+DCV has shown more efficacy as compared to $\mathrm{SOF}+\mathrm{RBV}(p=0.035)$ or to $\mathrm{SOF}+\mathrm{SIM} \pm \mathrm{RBV}(p=0.009)$.

Exploratory analyses revealed that among patients with non-genotype $1 \mathrm{HCV}$ infection and fibrosis F3, the rates of SVR were consistently high across subgroups (Table 2). Rates of SVR among patients with cirrhosis varied according to the combination of treatment and the lower rate was observed in the $\mathrm{SOF}+\mathrm{SIM} \pm \mathrm{RBV}$ group (73\%). However, the overall rate of SVR12 in cirrhotic patients was $78 \%$ vs $91 \%$ in patients with fibrosis F3. Among treatment-naive patients, the rates of SVR were comparable among the 3 groups $(85 \%$ in $\mathrm{SOF}+\mathrm{RBV}, 93 \%$ in $\mathrm{SOF}+\mathrm{DCV}$, and $83 \%$ in $\mathrm{SOF}+\mathrm{SIM} \pm \mathrm{RBV})$.

In an exploratory multivariate regression analysis of patient characteristics, 4 baseline factors (serum albumin, fibrosis, age, and gender) were independently associated with SVR12 in each therapy combination (data not shown).

\section{Safety profile of different SOF combinations}

The most common AEs observed were fatigue (27\%), headache (18\%), and nausea (19\%) (Table 3). Three patients who had HCV RNA undetectable at week 8 discontinued treatment due to serious AEs during the treatment period (HCC in 2 patients and a hepatic decompensation with variceal bleeding in 1 patient) (Table 3 ). The most common grade 3 laboratory abnormalities were low hemoglobin level and platelet counts. The mean change in the hemoglobin level associated with regimens that contained $\mathrm{RBV}$ versus those that did not contain $\mathrm{RBV}$ was $-2.4 \mathrm{~g} / \mathrm{dL}$ versus $-0.4 \mathrm{~g} / \mathrm{dL}$ after 12 weeks of therapy. The RBV dose was reduced in 19 patients because of anemia. All AEs were resolved and none was considered to be treatment related, consistent with changes in laboratory values typically associated with RVB. Decreases in hemoglobin levels and increases in reticulocytes and platelets counts, from baseline, were observed during treatment.

\section{Factors associated with treatment failure in patients with advanced fibrosis}

The prevalence of baseline risk factors in patients with $\mathrm{CHC}$ treated with SOF-based IFN-free treatment is presented in

Table 2 Responses rates according to SVRI 2

\begin{tabular}{|c|c|c|c|c|c|c|}
\hline & All & SOF+RBV & SOF+DCV & SOF+SIM $\pm R B V$ & p-value & \\
\hline & $N=383$ & $\begin{array}{l}n=161 \\
I\end{array}$ & $\begin{array}{l}n=144 \\
2\end{array}$ & $\begin{array}{l}n=78 \\
3\end{array}$ & (I vs 2$)$ & (2 vs 3$)$ \\
\hline Treatment failure & $44(11 \%)$ & $22(17 \%)$ & $8(5 \%)$ & $14(18 \%)$ & & \\
\hline \multicolumn{7}{|l|}{ Overall response } \\
\hline Number of patients & $322 / 383$ & 132 & 132 & 62 & & \\
\hline Percent $(95 \% \mathrm{Cl})$ & $85(8 I-88)$ & $82(76-88)$ & $92(86-95)$ & $79(70-88)$ & 0.035 & 0.009 \\
\hline \multicolumn{7}{|l|}{ Naive patients } \\
\hline Number of patient & $155 / 176$ & 56 & 75 & 24 & & \\
\hline Percent $(95 \% \mathrm{Cl})$ & $87(82-92)$ & $85(74-92)$ & $93(85-96)$ & $83(65-92)$ & & \\
\hline \multicolumn{7}{|c|}{ Patients previously treated } \\
\hline Number of patient & $167 / 207$ & 76 & 53 & 38 & & \\
\hline Percent $(95 \% \mathrm{Cl})$ & $81(75-85)$ & $80(7 \mid-87)$ & $84(73-91)$ & 77 (64-87) & & \\
\hline \multicolumn{7}{|l|}{ Fibrosis F3 } \\
\hline Number of patients & $161 / 177$ & 62 & 75 & 24 & & \\
\hline Percent $(95 \% \mathrm{Cl})$ & 91 (86-94) & $89(80-95)$ & $91(83-96)$ & $92(76-98)$ & & \\
\hline \multicolumn{7}{|l|}{ Fibrosis F4 } \\
\hline Number of patients & $161 / 206$ & 70 & 53 & 38 & & \\
\hline Percent $(95 \% \mathrm{Cl})$ & $78(72-83)$ & $76(66-84)$ & $85(75-92)$ & $73(60-83)$ & & \\
\hline \multicolumn{7}{|l|}{ Genotype I patients } \\
\hline Number of patients & $193 / 236$ & 94 & 88 & 11 & & \\
\hline Percent $(95 \% \mathrm{Cl})$ & $82(76-86)$ & $78(70-85)$ & $86(78-92)$ & $76(52-92)$ & & \\
\hline \multicolumn{7}{|c|}{ Non-genotype I patients } \\
\hline Number of patients & $129 / 147$ & 38 & 40 & 51 & & \\
\hline Percent $(95 \% \mathrm{Cl})$ & $88(8 I-92)$ & $93(80-97)$ & 95 (84-99) & $80(68-87)$ & & \\
\hline
\end{tabular}

Abbreviations: $\mathrm{Cl}$, confidence interval; SOF, sofosbuvir; RBV, ribavirin; DCV, daclatasvir; SIM, simeprevir; SVRI2, sustained virological response 12 weeks after cessation of therapy. 
Table 3 Reasons for treatment discontinuation and adverse events (AEs) in 383 patients

\begin{tabular}{|c|c|c|c|c|c|c|c|}
\hline & \multirow{2}{*}{$\begin{array}{l}\text { Overall } \\
N=383\end{array}$} & \multirow{2}{*}{$\begin{array}{l}\text { SOF+RBV } \\
n=|6|\end{array}$} & \multirow{2}{*}{$\begin{array}{l}\text { SOF+DCV } \\
n=144\end{array}$} & \multirow{2}{*}{$\begin{array}{l}\text { SOF+SIM } \pm R B V \\
n=78\end{array}$} & \multicolumn{3}{|l|}{$p$-value } \\
\hline & & & & & (16I vs I44) & (144 vs 78$)$ & (16I vs 78) \\
\hline \multicolumn{8}{|l|}{ Discontinuation of treatment } \\
\hline Due to lack of efficacy & $2(<1 \%)$ & $\mathrm{I}(\mathrm{l} \%)$ & 0 & $\mathrm{I}(1 \%)$ & NS & NS & NS \\
\hline Due to $A E / S A E$ & $3(1 \%)$ & $2(1 \%)$ & $\mathrm{I}(\mathrm{I} \%)$ & 0 & NS & NS & NS \\
\hline Due to other reasons* & $9(2 \%)$ & $4(2 \%)$ & $3(2 \%)$ & $\mathrm{I}(1 \%)$ & NS & NS & NS \\
\hline \multicolumn{8}{|l|}{ SAE } \\
\hline $\mathrm{HCC}$ & $2(1 \%)$ & $\mathrm{I}(<\mathrm{I} \%)$ & I (I\%) & 0 & NS & NS & NS \\
\hline Hepatic decompensation & $\mathrm{I}(<\mathrm{I} \%)$ & $\mathrm{I}(<\mathrm{I} \%)$ & 0 & 0 & NS & NS & NS \\
\hline \multicolumn{8}{|l|}{ Common AEs } \\
\hline Anemia & $61(16 \%)$ & $36(22 \%)$ & $3(2 \%)$ & $22(28 \%)$ & 0.001 & 0.001 & NS \\
\hline Dyspnea & $9(2 \%)$ & $5(3 \%)$ & $\mathrm{I}(\mathrm{l} \%)$ & $3(4 \%)$ & NS & NS & NS \\
\hline Fatigue & $104(27 \%)$ & $39(24 \%)$ & $49(34 \%)$ & $16(21 \%)$ & 0.119 & 0.039 & NS \\
\hline Flu-like symptoms & $33(9 \%)$ & $11(7 \%)$ & $13(9 \%)$ & $9(11 \%)$ & NS & NS & NS \\
\hline Headache & $70(18 \%)$ & $19(12 \%)$ & $40(28 \%)$ & II (I4\%) & 0.004 & 0.015 & NS \\
\hline Irritability & $25(7 \%)$ & II (7\%) & $7(5 \%)$ & $7(9 \%)$ & NS & NS & NS \\
\hline Memory loss & $18(5 \%)$ & $5(3 \%)$ & $12(8 \%)$ & $\mathrm{I}(1 \%)$ & NS & NS & 0.036 \\
\hline Nausea & 71 (19\%) & $26(16 \%)$ & $35(24 \%)$ & $10(13 \%)$ & NS & 0.157 & NS \\
\hline Photosensitivity & $9(2 \%)$ & $2(1 \%)$ & I $(<1 \%)$ & $6(8 \%)$ & NS & NS & NS \\
\hline Rash & $29(6 \%)$ & $18(11 \%)$ & $3(2 \%)$ & $8(10 \%)$ & 0.009 & 0.017 & NS \\
\hline
\end{tabular}

Note: *Three patients moved from Paris, 2 patients did not continue due to lack of heath assurance, and I did not adhere to treatment.

Abbreviations: AEs, adverse events; NS, not significant; SOF, sofosbuvir; RBV, ribavirin; DCV, daclatasvir; SIM, simeprevir; SAE, serious adverse event; HCC, hepatocellular carcinoma.

Table 1. Among the 44 patients (11\%) who failed to treatment, $17 \%$ were treated with SOF+RBV, $5 \%$ with SOF+DCV, and $18 \%$ with SOF+SIM \pm RBV. Overall, patients with cirrhosis (Metavir score F4) represented $91 \%$ of patients who did not respond to treatment. Metavir score F4, ratio of aspartate aminotransferase (AST)/alanine aminotransferase (ALT), and serum albumin level were the common risk factors independently associated with treatment failure in the 3 combination groups as analyzed by multivariate analysis (Table 4). Only a baseline age $\geq 53$ years ( $p=0.021$ ) was independently associated with treatment failure in patients treated with SOF+DCV as analyzed by multivariate analysis.

Gender was independently associated with treatment failure in patients treated with SOF+RBV $(p=0.023)$ and in patients treated with $\mathrm{SOF}+\mathrm{SIM} \pm \mathrm{RBV}(p=0.011)$.

\section{Discussion}

Our study aimed to extend the data obtained by the registration trials of SOF-based treatments and to describe important real-life data from more than 350 difficult-to-treat patients.

Most patients treated with SOF-based regimens had an SVR12 (85\%) regardless of viral subtype or failure of prior treatment, and $78 \%$ of patients had cirrhosis. These findings are generally consistent with clinical trial data and previous real-life data. ${ }^{9,11,16,17}$ The most common AE observed was fatigue, which was reported in approximately one-third of patients (27\%).
In our study, a higher number of patients with cirrhosis were included (54\%) as compared to the inclusion in the registration trials $(24 \%)$ and previous real-life analyses (30-44\%). ${ }^{5,8,18}$ Of note, one-third of our patients would have been ineligible for the various registration trials of SOF-based regimens, ${ }^{15} 17$ patients had Child Pugh B score, 4 patients had a history of liver decompensation, and 201 (52\%) had a history of partial or null response in previous treatment (including DAAs-experienced patients). Astonishingly, these patients displayed a reasonable chance for SVR. The overall frequency of SVR12 in patient with cirrhosis in our "real-life" cohort (73\%) was as well as comparable to those reported in clinical trial ${ }^{11,19}$ and 2 previous real-life studies (75\% in TRIO network and 79\% in HCV-TARGET study). ${ }^{9}$

The frequency of treatment failure at week 12 following EOT was slightly higher in a previous "real-life" data (21\%) and in clinical trials. Interestingly, in our cohort, only $11 \%$ of patients experienced a treatment failure until week12 (22 patients in SOF+RBV, 8 patients in SOF+DCV, and 14 patients in $\mathrm{SOF}+\mathrm{SIM} \pm \mathrm{RBV}$ groups).

Moreover, 5 predictors associated to treatment failure were found in multivariate regression analysis. Metavir score F4, low serum albumin, and ratio of AST/ALT at baseline were the only common independent predictors of treatment failure in our cohort. However, absence of cirrhosis, female sex, and age $<50$ years have been identified as key factors 
Table 4 Multivariate analysis of baseline factors associated with SVRI 2 in 383 patients with advanced fibrosis according to antiviral therapies

\begin{tabular}{|c|c|c|c|c|c|c|}
\hline & \multicolumn{2}{|l|}{ SOF+RBV } & \multicolumn{2}{|l|}{ SOF+DCV } & \multicolumn{2}{|l|}{ SOF+SIM $\pm R B V$} \\
\hline & OR $[95 \% \mathrm{Cl}]$ & $p$-value & OR $[95 \% \mathrm{Cl}]$ & p-value & OR $[95 \% \mathrm{Cl}]$ & $p$-value \\
\hline Age ( $<53$ vs $\geq 53$ years) & $1.00[0.96-1.25]$ & 0.048 & $1.12[1.04-1.32]$ & 0.021 & $1.07[1.00-1.44]$ & 0.059 \\
\hline Gender ( $F$ vs $M)$ & $1.36[1.23-2.14]$ & 0.023 & 1.17 [0.96-1.64] & 0.071 & $1.31[1.27-1.86]$ & 0.011 \\
\hline $\operatorname{BMI}\left(<30 \mathrm{vs} \geq 30 \mathrm{~kg} / \mathrm{m}^{2}\right)$ & $0.97[0.76-1.02]$ & 0.298 & $0.84[0.6 \mathrm{I}-1.07]$ & 0.463 & $0.89[0.73-1.22]$ & 0.222 \\
\hline Diabetes (+ vs -) & $\mathrm{I} .05[0.7 \mathrm{I}-2.20]$ & 0.424 & $0.67[0.21-1.08]$ & 0.602 & $0.64[0.48-1.34]$ & 0.254 \\
\hline Hypertension (+ vs -) & $0.54[0.31-1.03]$ & 0.105 & $0.28[0.13-1.21]$ & 0.378 & $0.59[0.43-1.01]$ & 0.754 \\
\hline Ratio AST/ALT (cont) & $2.09[1.91-3.99]$ & 0.014 & $1.46[1.30-2.76]$ & 0.027 & $\mathrm{I} .64[1.4 \mathrm{I}-2.63]$ & 0.030 \\
\hline Serum albumin (cont) & $1.85[1.70-2.82]$ & 0.001 & $1.49[0.99-1.86]$ & 0.082 & $2.05[1.23-3.08]$ & 0.017 \\
\hline Bilirubin (cont) & $1.02[0.88-1.05]$ & 0.082 & $0.97[0.83-1.00]$ & 0.124 & $1.05[0.91-2.63]$ & 0.190 \\
\hline Creatinine (cont) & $1.28[0.73-2.21]$ & 0.378 & $0.99[0.39-1.01]$ & 0.509 & $0.99[0.73-1.34]$ & 0.334 \\
\hline Platelet counts (cont) & $1.00[1.00-1.03]$ & 0.071 & $0.98[0.90-1.07]$ & 0.132 & $1.02[1.00-1.07]$ & 0.061 \\
\hline Prothrombin (cont.) & $0.92[0.86-1.04]$ & 0.096 & $0.96[0.91-1.08]$ & 0.306 & 1.01 [0.97-1.03] & 0.065 \\
\hline HCV RNA (<6 vs $\geq 6$ log) & $0.99[0.73-1.34]$ & 0.954 & $0.54[0.27-1.00]$ & 0.468 & $0.98[0.88-1.19]$ & 0.409 \\
\hline Genotype (non-I vs I) & $0.94[0.79-1.08]$ & 0.245 & $1.03[0.89-1.05]$ & 0.105 & $0.97[0.67-1.27]$ & 0.318 \\
\hline Metavir score (F3 vs F4) & $2.45[1.46-4.13]$ & 0.008 & $1.55[1.16-2.78]$ & 0.038 & $2.19[1.61-4.34]$ & 0.014 \\
\hline Previous treatment & $0.91[0.83-1.74]$ & 0.283 & $0.85[0.55-1.84]$ & 0.197 & $0.89[0.63-1.64]$ & 0.514 \\
\hline
\end{tabular}

Note: Multivariate regression analyses with $p$-value statistically significant $(p<0.05)$.

Abbreviations: F, female; M, male; BMI, body mass index; SOF, sofosbuvir; RBV, ribavirin; DCV, daclatasvir; SIM, simeprevir; cont, continuous variable; OR, odds ratio; Cl, confidence interval; HCV, hepatitis C virus; AST, aspartate aminotransferase; ALT, alanine aminotransferase; SVRI2, sustained virological response 12 weeks after cessation of therapy.

independently associated with SVR in patients treated with SOF-based regimens in previous study.

Our findings confirm that patients with risk factors of cirrhosis remain difficult to treat. Of note, those patients should be treated with special care since they are most likely to display risk factors for complications and treatment failure.

The safety of different combinations was in accordance with previous preliminary real-life reports. We saw a comparable incidence of AEs especially in patients with severe cirrhosis (Child Pugh B). Counterintuitively, patients with severe cirrhosis displayed neither a higher rate of treatment failures nor a higher risk of AEs incidence. ${ }^{8,16,20,21}$ The overall frequency of SAE was lower than in a previous study conducted by Shiffman et $\mathrm{al}^{12}(1.4 \%$ vs $9.1 \%)$. Of note, the age ( 52 vs 63 years), proportion of Caucasian (80\% vs 48\%), and Child Pugh B/C score (8\% vs 33\%) were different in our cohort compared to Schiffman et al's study. ${ }^{12}$ However, the discrepancy observed in SVR12 rates between the 3 groups might be due to the proportion of HCV G1a or the prevalence of interleukin (IL) 28 polymorphism CT and TT genotypes, which were not investigated. While IL28B polymorphism is the strongest pretreatment predictor for SVR in Pegylated-IFN (Peg-IFN)-/RBV-based treatment, ${ }^{22}$ our results confirm previous reports of limited practical value of IL28B polymorphism for prediction of SVR in patients treated with DDAs in real life.

Our data also indicate that oral therapy may be a reasonable option for some Peg-IFN- and DAA-experienced patients, as well as patients with compensated cirrhosis. ${ }^{12,18}$ This is an important finding, since the number of difficultto-treat patients will rapidly increase in the near future accordingly to the future burden of HCV-related morbidity and mortality. ${ }^{23}$

Our study has certain limitations. First, a minority of patients $(<27 \%)$ without liver biopsy were formally included, although all of these patients had 2 noninvasive liver examinations showing signs of liver cirrhosis. Second, the allocation of treatment was based on the willing of the practitioner. That may lead to an imbalance between the different combinations. Likewise, the use of RBV is not required with every oral DAA regimen, including the SOF and DCV combination, which has a high antiviral potency and high resistance barrier. RBV-sparing regimens are desirable, considering the risks of anemia and teratogenicity, but their role from a cost-effectiveness perspective (i.e, allowing a reduction in treatment duration) cannot be excluded. Third, our cohort included patients who were previously treated with Peg-IFN or first-generation polymerase inhibitors. Our study reflects the "real-life" situation in many large tertiary referral centers and provides important learning points in these "difficult-totreat" patients with DAAs combinations.

\section{Conclusion}

Oral HCV SOF-based treatments are associated with high rates of SVR12 and a good tolerance for patients with both fibrosis F3 and cirrhosis F4, in real life. 


\section{Disclosure}

Blaise K Kutala, Feryel Mouri, Corinne Castelnau, Valerie Bouton, Nathalie Giuily, and Nathalie Boyer certify that they have no affiliations with or involvement in any organization or entity with any financial interest (such as honoraria; educational grants; participation in speakers' bureaus; membership, employment, consultancies, stock ownership, or other equity interest; and expert testimony or patent-licensing arrangements), or non-financial interest (such as personal or professional relationships, affiliations, knowledge, or beliefs) in the subject matter or materials discussed in this manuscript.

Tarik Asselah and Patrick Marcellin report the following details of affiliation or involvement in an organization or entity with a non-financial interest in the subject matter or materials discussed in this manuscript. They are speaking and teaching and attending advisor commitee for Roche, Novartis, Bayer, BMS, Gilead Science, Merck, Janssen, and AbbVie. The authors report no other conflicts of interest in this work.

\section{References}

1. Lavanchy D. Evolving epidemiology of hepatitis C virus. Clin Microbiol Infect. 2011;17:107-115.

2. Cornberg M, Razavi HA, Alberti A, et al. A systematic review of hepatitis $\mathrm{C}$ virus epidemiology in Europe, Canada and Israel: systematic review of HCV epidemiology in Europe. Liver Int. 2011;31:30-60.

3. Negro F. Epidemiology of hepatitis C in Europe. Dig Liver Dis. 2014;46: S158-S164.

4. Backus LI, Belperio PS, Shahoumian TA, Cheung R, Mole LA. Comparative effectiveness of the hepatitis $\mathrm{C}$ virus protease inhibitors boceprevir and telaprevir in a large U.S. cohort. Aliment Pharmacol Ther. 2014;39:93-103.

5. Jensen DM, O'Leary J, Pockros P, et al. Safety and efficacy of sofosbuvir-containing regimens for hepatitis $\mathrm{C}$ : real-world experience in a diverse, longitudinal observational cohort. In: Fifth Annual Meeting of the American Association for the Study of Liver Diseases; Nov 7-11, 2014; Boston, MA.

6. Hézode C, Fontaine H, Dorival C, et al. Triple therapy in treatmentexperienced patients with HCV-cirrhosis in a multicentre cohort of the French Early Access Programme (ANRS CO20-CUPIC) NCT01514890. J Hepatol. 2013;59:434-441.

7. Gutierrez JA, Lawitz EJ, Poordad F. Interferon-free, direct-acting antiviral therapy for chronic hepatitis C. J Viral Hepat. 2015;22:861-870.

8. Maan R, van Tilborg M, Deterding K, et al. Safety and effectiveness of direct-acting antiviral agents for treatment of patients with chronic hepatitis $\mathrm{C}$ virus infection and cirrhosis. Clin Gastroenterol Hepatol. 2016;14:1821.e6-1830.e6.
9. Dieterich D, Bacon B, Flamm S, et al. Evaluation of sofosbuvir and simeprevir-based regimens in the TRIO network: academic and community treatment of a real-world, heterogeneous population. In: Fifth Annual Meeting of the American Association for the Study of Liver Diseases; Nov 7-11, 2014; Boston, MA.

10. Kwo P, Gitlin N, Nahass R, et al. Simeprevir plus sofosbuvir (12 and 8 weeks) in hepatitis $\mathrm{C}$ virus genotype 1 -infected patients without cirrhosis: OPTIMIST-1, a phase 3, randomized study. Hepatology. 2016;64: 370-380.

11. Lawitz E, Matusow G, DeJesus E, et al. Simeprevir plus sofosbuvir in patients with chronic hepatitis $\mathrm{C}$ virus genotype 1 infection and cirrhosis: a phase 3 study (OPTIMIST-2). Hepatology. 2016;64:360-369.

12. Shiffman ML, James AM, Long AG, Alexander PC. Treatment of chronic HCV with sofosbuvir and simeprevir in patients with cirrhosis and contraindications to interferon and/or ribavirin. Am J Gastroenterol. 2015;110:1179-1185.

13. Sulkowski MS, Gardiner DF, Rodriguez-Torres M, et al. Daclatasvir plus sofosbuvir for previously treated or untreated chronic HCV infection. N Engl J Med. 2014;370:211-221.

14. Zeuzem S, Dusheiko GM, Salupere R, et al. Sofosbuvir and ribavirin in HCV genotypes 2 and 3. N Engl J Med. 2014;370:1993-2001.

15. Review edition: Highlights in the treatment of hepatitis $C$ virus from the 2014 liver meeting: a review of selected presentations from the 2014 liver meeting November 7-11, 2014. Gastroenterol Hepatol. 2014;10: $1-19$.

16. Mehta R, Kabrawala M, Nandwani S, Tekriwal R, Nandania P. Early experience of sofosbuvir based combination therapy in "reallife" cohort with chronic hepatitis-C infection. J Clin Diagn Res. 2017;11:OC05-OC08.

17. Hlaing NKT, Mitrani RA, Aung ST, et al. Safety and efficacy of sofosbuvir-based DAA regimens for hepatitis $\mathrm{C}$ virus genotypes 1-4 and 6 in Myanmar: real-world experience. JViral Hepat. 2017;24(11): 927-935.

18. Saxena V, Nyberg L, Pauly M, et al. Safety and efficacy of simeprevir/ sofosbuvir in hepatitis C-infected patients with compensated and decompensated cirrhosis. Hepatology. 2015;62:715-725.

19. Nelson DR, Cooper JN, Lalezari JP, et al. All-oral 12-week treatment with daclatasvir plus sofosbuvir in patients with hepatitis $\mathrm{C}$ virus genotype 3 infection: ALLY-3 phase III study. Hepatology. 2015;61: $1127-1135$.

20. Lawitz E, Poordad F, Brainard DM, et al. Sofosbuvir with peginterferonribavirin for 12 weeks in previously treated patients with hepatitis $\mathrm{C}$ genotype 2 or 3 and cirrhosis. Hepatology. 2015;61:769-775.

21. Maasoumy B, Port K, Markova AA, et al. Eligibility and safety of triple therapy for hepatitis $\mathrm{C}$ : lessons learned from the first experience in a real world setting. PLoS One. 2013;8:e55285.

22. Thompson AJ, Muir AJ, Sulkowski MS, et al. Interleukin-28B polymorphism improves viral kinetics and is the strongest pretreatment predictor of sustained virologic response in genotype 1 hepatitis $\mathrm{C}$ virus. Gastroenterology. 2010;139:120.e18-129.e18.

23. Rein DB, Wittenborn JS, Weinbaum CM, Sabin M, Smith BD, Lesesne SB. Forecasting the morbidity and mortality associated with prevalent cases of pre-cirrhotic chronic hepatitis C in the United States. Dig Liver Dis. 2011;43:66-72.
Hepatic Medicine: Evidence and Research

\section{Publish your work in this journal}

Hepatic Medicine: Evidence and Research is an international, peerreviewed, open access journal covering all aspects of adult and pediatric hepatology in the clinic and laboratory including the following topics: Pathology, pathophysiology of hepatic disease; Investigation and treatment of hepatic disease; Pharmacology of drugs used for the treatment

\section{Dovepress}

of hepatic disease. Issues of patient safety and quality of care will also be considered. The manuscript management system is completely online and includes a very quick and fair peer-review system, which is all easy to use. Visit http://www.dovepress.com/testimonials.php to read real quotes from published authors. 